\title{
Combining Several Thermal Indices to Generate a Unique Heat Comfort Assessment Methodology
}

\author{
Wissam EL Hachem ${ }^{1}$, Joseph Khoury ${ }^{2}$, Ramy Harik ${ }^{3}$ \\ ${ }^{1}$ University of Bergen (Norway), ${ }^{2}$ Methode Electronics Inc. (Germany), ${ }^{3}$ University of South Carolina (United States) \\ wha004@uib.no,joseph.khoury@methodegermany.com,_harik@.ce.sc.edu
}

Received: May 2015

Accepted: September 2015

\section{Abstract:}

Purpose: The proposed methodology hopes to provide a systematic multi-disciplinary approach to assess the thermal environment while minimizing unneeded efforts.

Design/methodology/approach: Different factors affect the perception of the human thermal experience: metabolic rate (biology), surrounding temperatures (heat balance and environmental factors) and cognitive treatment (physiology).This paper proposes a combination of different multidisciplinary variables to generate a unique heat comfort assessment methodology. The variables at stake are physiological, biological, and environmental. Our own heat analysis is thoroughly presented and all relevant equations are described.

Findings: Most companies are oblivious about potential dangers of heat stress accidents and thus about methods to monitor and prevent them. This methodology enables the company or the concerned individual to conduct a preliminary assessment with minimal wasted resources and time in unnecessary steps whilst providing a guideline for a detailed study with minimal error rates if needed. More so, thermal comfort is an integral part of sound ergonomics practices, which in turn are decisive for the success of any lean six sigma initiative.

Research limitations/implications: This methodology requires several full implementations to finalize its design. 
Originality/value: Most used heat comfort models are inherently uncertain and tiresome to apply.An extensive literature review confirms the need for a uniform assessment methodology that combines the different thermal comfort models such as the Fanger comfort model (PMV, PPD) and WGBT since high error rates coupled with tiresome calculations often hinder the thermal assessment process.

Keywords: heat index, comfort assessment, WBGT, Fanger Comfort Model, globe temperature

\section{Introduction}

Lean six sigma is recognized as the way to develop an adaptive competitive company. Ergonomics and safety are an integral part of lean six sigma (Kumar, Kumar, Haleem \& Gahlot, 2013), and they should be recognized as crucial for designing robust production systems rather than simply limited to health issues (Othman, Gouw \& Bhuiyan, 2012). More so, lean manufacturing stresses the importance of worker's moral and productivity which can be significantly boosted by ensuring proper indoor environmental quality. Hence the need for companies to realize the importance of maintaining a comfortable environment for their workers. The assessment of the thermal environment is a major index in such an effort. Different factors affect the perception of the human thermal experience: metabolic rate (biology), surrounding temperatures (heat balance and environmental factors) and cognitive treatment (physiology). This paper proposes a combination of these different personal and environmental variables to compute a unique heat comfort methodology assessment. At first, a brief introduction of the work and its motivation is presented. Following, a state of the art is presented detailing different thermal comfort models such as the Fanger comfort model (PMV, PPD) and WGBT. Then, we will present our own heat analysis methodology that combines different measurements and indexes to propose a final recommendation. Finally, a full case study at an industrial partner is presented before concluding with perspectives to further enhance the proposed assessment.

\section{Literature Review}

Modern day Industrial Engineers (IE) are required to possess a set of skills to keep up with the ever changing workplace. Lean six sigma is always part of such a set of skills (Marksberry \& Parsley, 2011), which in turn requires IE's to devote time and effort on issues that deal with ergonomics. Worker's productivity in the workplace, consequently their safety and occupational health have been under the industry's prime light as recent studies deduced that worker's productivity is directly related to his job satisfaction, especially in developing countries. 
(Ismail, Rani, Makhbul \& Deros, 2009) states that where workers have most to gain from a proper workplace, often find themselves in a poorly designed one, with a gap between their skill range and their job responsibilities. Indoor environmental quality has been primal when investigating the worker satisfaction. Thermal comfort occupies a central role in the endeavor to improve workers productivity-satisfaction relationship. It can be stated that thermal comfort is achieved when our state of mind is content with our thermal surroundings. (Lu, 2008) attributes heat with over $66 \%$ when assessing top occupational hazards. Heat is mainly associated with exhaustion related incidents. Also, logistic regression proves that there is a correlation between worker conditions, including environmental ones, and their physical and psychosocial health and subsequently their productivity. (Alahmer, 2009) says that since heat assessment is a highly subjective concept, a great variety of approaches were adopted when assessing it. In short they are the human physiological, psychological and thermal manikin approaches. Human physiological models divide the human body into discrete segments composed of the core, the muscle, the fat and the skin tissue, or of the human tissue and the thermoregulatory system (vasomotor control, sweating and shivering). However, these models prove hard to construct with questionable outcome validity due to the complexity of our body shapes. Human psychological models rely on physiological indicators to determine our thermal sensation associated with such responses. They generally integrate relevant environmental factors (temperature, wind velocity, relative humidity...) in a manner to reproduce out thermal sensations. Main indices are Predicted Mean Vote (PMV) and Percentage of People Dissatisfied (PPD). Thermal manikins are mainly utilized to have a safer alternative then exposing human subjects to extreme conditions. They are now lost cost, high tech with the advantage of combining the physiological and psychological models. They are primarily used to assess clothing heat transfer and the response of our bodies to the thermal environment. This approach has been validated in comparison with the previous approaches, with high similarities in the results except for the feet and head. (Wildeboor \& Camp, 1993) discusses how a health monitoring system could be put in order to prevent unnecessary heat stress accidents. Such a program would gather information on heat acclimatization, water intake, diet programs and possible heat illness history. Employees exposed to hot environments have to be introduced and trained to recognize heat stress symptoms and how to prevent it using dietary, hydration, clothing and personnel prevention techniques as well as primary knowledge of assessment techniques. (Chan, Michael Yam, Joanne Chung \& Wen, 2012) uses a relatively simple heat stress index, HI (or Heat Index) which combines the temperature and $\mathrm{RH} \%$ to assess how the physiological responses are correlated with environmental parameters, with promising results of lowering heat stress related fatalities. ( $\mathrm{Ai}, \mathrm{Mak}, \mathrm{Niu} \& \mathrm{Li}, 2011$ ) says that a natural ventilation system would render the indoor temperature fluctuations between different nodes minimal, aiding in relaxing the thermal comfort zone. Occupants of naturally ventilated buildings would tolerate higher temperatures because of the unique physiological and psychological response combination. So, it is always a good idea to incorporate a natural ventilation system, whether open doors or natural ventilation driven HVAC system. (Budd, 
2008) investigates the most widely used heat stress index, Wet Bulb Globe Temperature or WBGT. It combines convection, radiation, humidity and wind velocity to the overall assessment of the thermal environment. Three independent parameters are measured to calculate the WBGT, Dry-Bulb temperature (DB), Wet-Bulb temperature (WB) and Globe temperature (GT). There are two different equations, one for indoor use where an assumption is made that the globe temperature is equal to the dry-bulb one and a higher coefficient is placed for the GT, and one for outside use where the three parameters are used. Many assumptions are made when computing the WBGT, mainly concerning the metabolic rate, the acclimatization conditions and clothing level. Its prime importance lies in the fact that it takes into consideration outside as well as indoor climate parameters and plenty of tables and graphs have been developed for it which ensures easy and valid outcomes. However, it has a serious drawback, since it does not have a full grasp on human physiology, mainly sweat evaporation and skin temperatures in high RH\% or low wind velocity, and any variation between actual and assumed parameters would require additional investigations. Also, the common neglect for radiant heat TG, whether in measuring it or simply by omitting it render the WBGT more limited in its validity range. So, WBGT is a great indicator of potential problems, however most probably only as an initial index. (Richards et al., 2008) confirmed the vital role of the clothing insulation in determining thermal comfort. A key concept marginally developed in current generic heat assessment methodologies such as the WBGT and the Fanger comfort model, is clothing permeability and moisture sorption and desorption under transient conditions which significantly increases the heat loss than simply summing the dry and evaporative heat loss. (Epstein \& Moran, 2006) discusses how to error proof the calculation of the WBGT by calculating another heat stress index, the Discomfort Index or DI. It is relatively easy to calculate since it has only two parameters, dry-bulb and wet-bulb, both measurable with low error rates by a Psychrometer. Empirical results state that there exists high correlation between the WBGT and DI, so the latter would prove extremely useful to validate the WBGT. (Dimiceli, Piltz \& Amber, 2011) proposes an algorithm to calculate the tiresome Globe Temperature or TG. This algorithm incorporates heat transfer coefficients, solar irradiance, zenith angle, thermal emissivity as well many other parameters, leading to a calculated TG within a $1 \%$ interval from the actual reading of it by proper equipment with the right calibration and adequate use. (Chamra, Steele \& Huynh, 2003) investigates the uncertainty of some heat stress indices, mainly the predicted mean vote or PMV. Despite proving to be able to predict accurately for most of the cases, the PMV's clothing insulation and activity level were shown to be main contributors to its uncertainty after a detailed uncertainty analysis. These two parameters are usually estimated based on experience or derived from tables, so little can be done to minimize their uncertainty. At low metabolic rates ( $<1 \mathrm{met}$ ), it proved to be generally acceptable. However at higher rates (> 2met) the $\mathrm{RH} \%$ plays a role in their validity. At mid to high $\mathrm{RH} \%$ and approximate wind velocity of $30 \mathrm{fpm}$, the comparison validated the PMV, however at lower $\mathrm{RH} \%$ and higher wind velocity above $50 \mathrm{fpm}$, it no longer validated. (Chen, Lin \& Wang, 2012) affirms that a proper assessment of the clothing level is necessary 
in order to properly validate the PMV calculation. Inner clothing, more difficult to visually assess plays a major role in moisture absorption and sweat evaporation, and directly affects the subjective assessment of the thermal environment and consequently the thermal comfort. (Wang, Gao, Kuklane \& Holmer, 2010) proposes a possible solution to the current rule of thumb estimation of clothing insulation level. It is the recently emerging heating garments equipped with smart technology and fabric. They offer the possibility of controlling the thermal properties of clothing while being efficient with significantly higher resistance to extreme conditions reducing cold/heat related incidents as well as minimal reduction in worker dexterity and performance. (Hancock \& Vasmatzidis, 2003) investigates the relationship between the heat stress and the cognitive performance of employees. One common result, is that the more cognitively demanding a job is, the lower the tolerance to heat tress versus the more simple tasks having a very high tolerance to heat stress, close to the physical collapse point. Recent studies have studied the possibility of relying on the WBGT in assessing the relationship between heat stress and cognitive performance. However, it is still early to conclude about its validity since the radiant heat impact is largely still unknown. (Chandra, Ghosh \& Barman, 2010) affirms the fact that cognitive demand in hot environment increase, especially with vision related tasks. Also, the reaction time RT increases after exercise and heat load, rendering human related errors more frequent, so tasks ought to be designed taking into account possible increase in cognitive demand after several hours of labor and possible hot environments.

Indoor environmental quality is directly linked with worker productivity. Many approaches were adopted when investigating its most hazardous component, the thermal environment. Two indices are noted as the most holistic as well as easy to assess, the WBGT and the [PMV,PPD]. Each has its limitations, the first not properly assessing many physiological parameters such as sweat evaporation, skin temperature,... etc, and the latter being more tiresome to calculate as well its inherent uncertainty. So, a multi-disciplinary approach is adopted in this paper, combining physiological, heat balance and environmental factors to propose a new methodology that combines these two indices with error proofing techniques to readily assess a given thermal environment and systematically conclude what parameters need to be focused on to relax the comfort zone.

\section{Background on Thermal Comfort Models}

\subsection{Overview}

Thermal comfort models are mathematical models which predict responses of the bodies to the thermal environment. The main heat variables are:

- Personal variables: 
- Thermal resistance of the clothing measured in units of "clo."

- Metabolic rate (met)

- Environmental variables:

- Dry-Bulb temperature (Ta)

- Mean Radiant Temperature (T_mrt)

- Relative air velocity (V)

- Water vapor pressure in ambient air (RH\%)

The table below lists the major parameters with their respective symbol and definition.

\begin{tabular}{|c|c|c|}
\hline Nomenclature & Symbol & Brief Definition \\
\hline Dry-Bulb & $\mathrm{T}_{\mathrm{a}}$ & $\begin{array}{l}\text { Temperature registered by the common thermostat with an unwetted } \\
\text { bulb shielded from radiant exchange }\end{array}$ \\
\hline Wet Bulb & $T_{w}$ & A means of expressing the humidity of the air \\
\hline Dew Point & DP & Temperature at which the water vapor starts to condensate \\
\hline $\begin{array}{l}\text { Mean Radiant } \\
\text { Temperature }\end{array}$ & MRT & $\begin{array}{l}\text { Equivalent uniform temperature of an enclosure causing the same } \\
\text { radiant exchange between the body and the surroundings }\end{array}$ \\
\hline Radiant heat & $T_{g}$ & Obtained with a globe thermometer to measure radiant heat \\
\hline Relative Humidity & $\mathrm{RH} \%$ & $\begin{array}{l}\text { Measures the current absolute humidity relative to the maximum for } \\
\text { that air pressure and temperature }\end{array}$ \\
\hline Metabolic Rate & M & Amount of energy expanded during a period of time \\
\hline Clothing & Clo & Relative measure of the ability of insulation to provide warmth \\
\hline Skin Temperature & $\mathrm{T}_{\mathrm{sk}}$ & $\begin{array}{l}\text { Temperature of the surface at radiative equilibrium. It forms the } \\
\text { interface between the body and atmosphere. }\end{array}$ \\
\hline Core Temperature & $T_{c r}$ & $\begin{array}{l}\text { The temperature of structures deep within the body, as opposed to } \\
\text { peripheral temperature such as that of the skin }\end{array}$ \\
\hline Skin Wettedness & $\mathrm{w}$ & $\begin{array}{l}\text { It is the proportion of the total skin surface area of the body covered } \\
\text { with sweat. }\end{array}$ \\
\hline $\begin{array}{l}\text { Thermal } \\
\text { Conductance }\end{array}$ & $\mathrm{K}$ & Ability of the body to transfer heat per unit time \\
\hline $\begin{array}{l}\text { Ratio of Body's } \\
\text { surface }\end{array}$ & $f_{\mathrm{cl}}$ & $\begin{array}{l}\text { Ratio of body's surface area when fully clothed to body's surface area } \\
\text { when nude }\end{array}$ \\
\hline $\begin{array}{l}\text { Convective heat } \\
\text { transfer }\end{array}$ & $h_{c}$ & Transfer of heat from one place to another by the movement of fluids \\
\hline Predicted Mean Vote & PMV & Represent a person vote on his thermal comfort on a scale of $\{-3,+3\}$ \\
\hline $\begin{array}{l}\text { Percentage of People } \\
\text { Dissatisfied }\end{array}$ & PPD & $\begin{array}{l}\text { It is a measure to capture people's subjectivity in assessing their } \\
\text { thermal environment }\end{array}$ \\
\hline
\end{tabular}

Table 1. Nomenclature Main heat computation variables

Here is a table illustrating how they relate to each other:

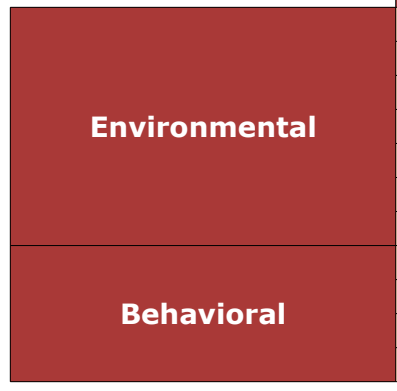

Parameter

Dry Bulb Temperature

$\mathrm{T}_{0}=0.5 *\left(\mathrm{~T}_{\mathrm{a}}+\mathrm{MRT}\right)$

$\left(T_{0} \cong(2 / 3) * T_{a}+(1 / 3) * T_{g}\right)$

Black-globe Temperature $\mathrm{MRT}=(1+0.22 * \mathrm{~V} 0.5)\left(\mathrm{T}_{\mathrm{g}}-\mathrm{T}_{\mathrm{a}}\right)+\mathrm{T}_{\mathrm{a}}$ Wind Velocity

Wet-Bulb temperature

Metabolic rate

Clothing

Insulation

Moisture permeability

\section{\begin{tabular}{l|l} 
Symbol & Also
\end{tabular}}

$\left(T_{a}\right)$

$\left(T_{g}\right)$

MRT

V)

\begin{tabular}{c|c} 
( $\left.T_{w}\right)$ & RH \\
\hline (M) & Met
\end{tabular}

Table 2. Key Heat Variables 
So a change of $1^{\circ} \mathrm{C}$ in MRT can be offset by a $1^{\circ} \mathrm{C}$ in $T_{a}$. Also, a change in $0.1 \mathrm{~m} / \mathrm{s}$ in wind speed is equivalent to a change in $0.5^{\circ} \mathrm{C}$ in $\mathrm{T}_{a}$ (Up to $1.5^{\circ} \mathrm{C}$ ). A $10 \%$ change in relative humidity can be offset by a $0.3^{\circ} \mathrm{C}$ in $\mathrm{T}_{\mathrm{a}}$.

Also, there are physiological variables that influence the conditions of thermal comfort:

- Skin Temperature (Tsk)

- Core or Internal Temperature (Tcr)

- Sweat Rate

- $\quad$ Skin Wettedness (w)

- Thermal Conductance $(\mathrm{K})$ between the core and skin

These physiological variables are part of Fanger's comfort model which will be introduced next; Mathematical models that simulate occupants' thermal response to their environment have been developed. Most thermal comfort prediction models use a seven or nine point thermal sensation scale, as in the following table:

\begin{tabular}{|c|c|c|c|c|}
\hline \multicolumn{2}{|c|}{ Vote } & Thermal sensation & Comfort sensation & Zone of thermal effect \\
\hline & 9 & Very hot & Very uncomfortable & \multirow{2}{*}{ Incompensable heat } \\
\hline 3 & 8 & Hot & uncomfortable & \\
\hline 2 & 7 & warm & \multirow{2}{*}{ Slightly uncomfortable } & Sweat evaporation \\
\hline 1 & 6 & Slightly warm & & Compensable \\
\hline 0 & 5 & Neutral & \multirow{2}{*}{ comfortable } & \multirow{2}{*}{ Vasometer compensable } \\
\hline-1 & 4 & Slightly cool & & \\
\hline-2 & 3 & Cool & \multirow{2}{*}{ Slightly uncomfortable } & \multirow{2}{*}{ Shivering compensable } \\
\hline-3 & 2 & Cold & & \\
\hline & & Very Cold & Uncomfortable & Incompensable cold \\
\hline
\end{tabular}

Table 3. Thermal Sensation Scales

The most accepted models have been developed by P.O. Fanger (the Fanger Comfort Model), the J. B. Pierce Foundation (the Pierce Two-Node Model), and researchers at Kansas State University (the KSU Two-Node Model).

All three models share a key methodology which is assessing the energy balance and relying on the energy exchange mechanisms coupled with empirically and experimentally set parameters to forecast the human thermal condition in an environment. What they differ in is some of the physiological parameters and the extent of their impact. 


\subsection{Fanger Comfort Model}

\subsubsection{Description of the Model and Algorithm}

It is the precursor to many other models and most probably the most widely used and developed. It uses the seven-point form of a thermal sensation scale. The model accounts for energy loss ( $L$ ): the convection and radiant heat loss from the outer surface of the clothing, the heat loss by water vapor diffusion through the skin, the heat loss by evaporation of sweat from the skin surface, the latent and dry respiration heat loss and the heat transfer from the skin to the outer surface of the clothing. Also, an assumption of a thermally steady state of the person with his environment is made.

A Predicted Mean Vote (PMV) is derived assessing how the energy loss ( $L$ ) deviates from the metabolic rate (M). The PMV works on the scale indicated in Table 4 below:

\begin{tabular}{|c|c|c|c|c|c|c|}
\hline Cold & Cool & Slightly cool & Neutral & Slightly warm & Warm & Hot \\
\hline-3 & -2 & -1 & 0 & 1 & 2 & 3 \\
\hline
\end{tabular}

Table 4. ASHRAE 7-point psycho-physical scale

\subsubsection{PMV and PPD}

The Predicted Mean Vote or PMV equation is as follows:

$$
\begin{gathered}
\left.P M V=0.303 * \mathrm{e}^{-0.036 \mathrm{M}}+0.028\right) *\left[(\mathrm{M}-\mathrm{W})-3.05 * 10^{-3}\left\{5733-6.99(\mathrm{M}-\mathrm{W})-\mathrm{P}_{\mathrm{a}}\right\}-0.42\{(\mathrm{M}-\mathrm{W})-\right. \\
58.15\}-1.7 * 10^{-5} * \mathrm{M}\left(5867-\mathrm{P}_{\mathrm{a}}\right)-0.0014 * \mathrm{M}\left(34-\mathrm{t}_{\mathrm{a}}\right)-3.96 * 10^{-8} * \mathrm{f}_{\mathrm{cl}}\left\{\left(\mathrm{t}_{\mathrm{cl}}+273\right) 4-\right. \\
\left.\left.\left(\mathrm{t}_{\mathrm{r}}+273\right) 4\right\}-\mathrm{f}_{\mathrm{cl}} * \mathrm{~h}_{\mathrm{c}} *\left(\mathrm{t}_{\mathrm{cl}}-\mathrm{t}_{\mathrm{a}}\right)\right]
\end{gathered}
$$

The following table partitions the PMV into its different components:

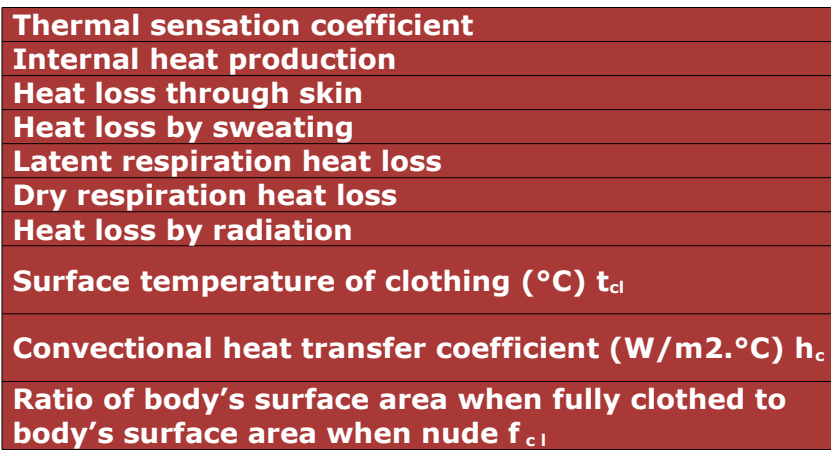

$0.303 * \mathrm{e}^{-0.036 \mathrm{M}}+0.028$
$\mathrm{M}-\mathrm{W}$
$3.05 * 10^{-3}\left\{5733-6.99(\mathrm{M}-\mathrm{W})-\mathrm{P}_{\mathrm{a}}\right.$
$0.42\{(\mathrm{M}-\mathrm{W})-58.15$
$1.7 * 10^{-5} * \mathrm{M}\left(5867-\mathrm{P}_{\mathrm{a}}\right)$
$0.0014 * \mathrm{M}\left(34-\mathrm{t}_{\mathrm{a}}\right)$
$3.96 * 10^{-8} * \mathrm{f}_{\mathrm{cl}}\left\{\left(\mathrm{t}_{\mathrm{cl}}+273\right)^{4}-\left(\mathrm{t}_{\mathrm{r}}+273\right)^{4}\right\}$
$35.7-0.028(\mathrm{M}-\mathrm{W})-0.1555 * \mathrm{I}_{\mathrm{cl}} *\left[3.96 * 10^{-8} * \mathrm{f}_{\mathrm{cl}} *\left\{\left(\mathrm{t}_{\mathrm{cl}}+\right.\right.\right.$
$\left.\left.273)^{4}-\left(\mathrm{t}_{\mathrm{r}}+273\right)^{4}\right\}+\mathrm{f}_{\mathrm{cl}} * \mathrm{~h}_{\mathrm{c}} *\left(\mathrm{t}_{\mathrm{cl}}-\mathrm{t}_{\mathrm{a}}\right)\right]$
$2.38 *\left(\mathrm{t}_{\mathrm{cl}}-\mathrm{t}_{\mathrm{a}}\right) 0.25$ for $2.38 *\left(\mathrm{t}_{\mathrm{cl}}-\mathrm{t}_{\mathrm{a}}\right) 0.25>12.1 * \sqrt{ } \mathrm{v}$
or, $12.1 * \sqrt{ } \mathrm{v}$ for $2.38 *\left(\mathrm{t}_{\mathrm{cl}}-\mathrm{t}_{\mathrm{a}}\right) 0.25<12.1 * \sqrt{ } \mathrm{v}$
$1.0+0.2 * \mathrm{CLO}$ for $\mathrm{I}_{\mathrm{cl}} \leq 0.4$ or
$1.05+0.1 * \mathrm{CLO}$ for $\mathrm{I}_{\mathrm{cl}}>0.4$

Table 5. PMV Components 
The PMV scale represents the mean vote of a person about his level of comfort. Since not all people are alike, Fanger also developed the Predicted Percentage of Dissatisfied or PPD index to provide a clearer measure of discomfort. The PPD index is derived from the PMV as follows:

$$
\mathrm{PPD}=100-95 * \mathrm{e}^{\left(-0.03353 * \mathrm{PMV}^{4}-0.2179 * \mathrm{PMV}^{2}\right)}
$$

When the average individual is neutral, i.e. $P M V=0,5 \%$ of the individuals will be dissatisfied with the thermal environment. Following ASHRAE 55: Thermal Environmental Conditions for Human Occupancy, the limits are set at $-0.5<$ PMV $<0.5$ and PPD $<10 \%$ for a thermally comfortable environment.

\subsection{WBGT Index}

Another important, probably more known, index is the Wet Bulb Globe Temperature (WBGT). It was developed by the US Navy as part of a study on heat related injuries during military training. It relates Dry Bulb $\left(T_{-} a\right)$, Wet Bulb $\left(T_{-} w\right)$ and Black globe $\left(T_{-} g\right)$ in the following equations:

$$
\begin{aligned}
& \text { WBGT }=0.7 * T_{w}+0.1 * T_{a}+0.2 * T_{g} \text { (for outdoor conditions) } \\
& \text { WBGT }=0.7 * T_{w}+0.3 * T_{g} \text { (for indoor conditions i.e. } T_{g}=T_{a} \text { ) }
\end{aligned}
$$

This index has little physiological correlation and the coefficients were deduced empirically. It is adopted as the standard of ISO and it will be elaborated in the next section.

\section{Heat Analysis Methodology}

\subsection{Logic}

The following chart (Figure 1) summarizes the main steps undertaken in this methodology towards estimating the current thermal condition and suggesting possible improvements. 


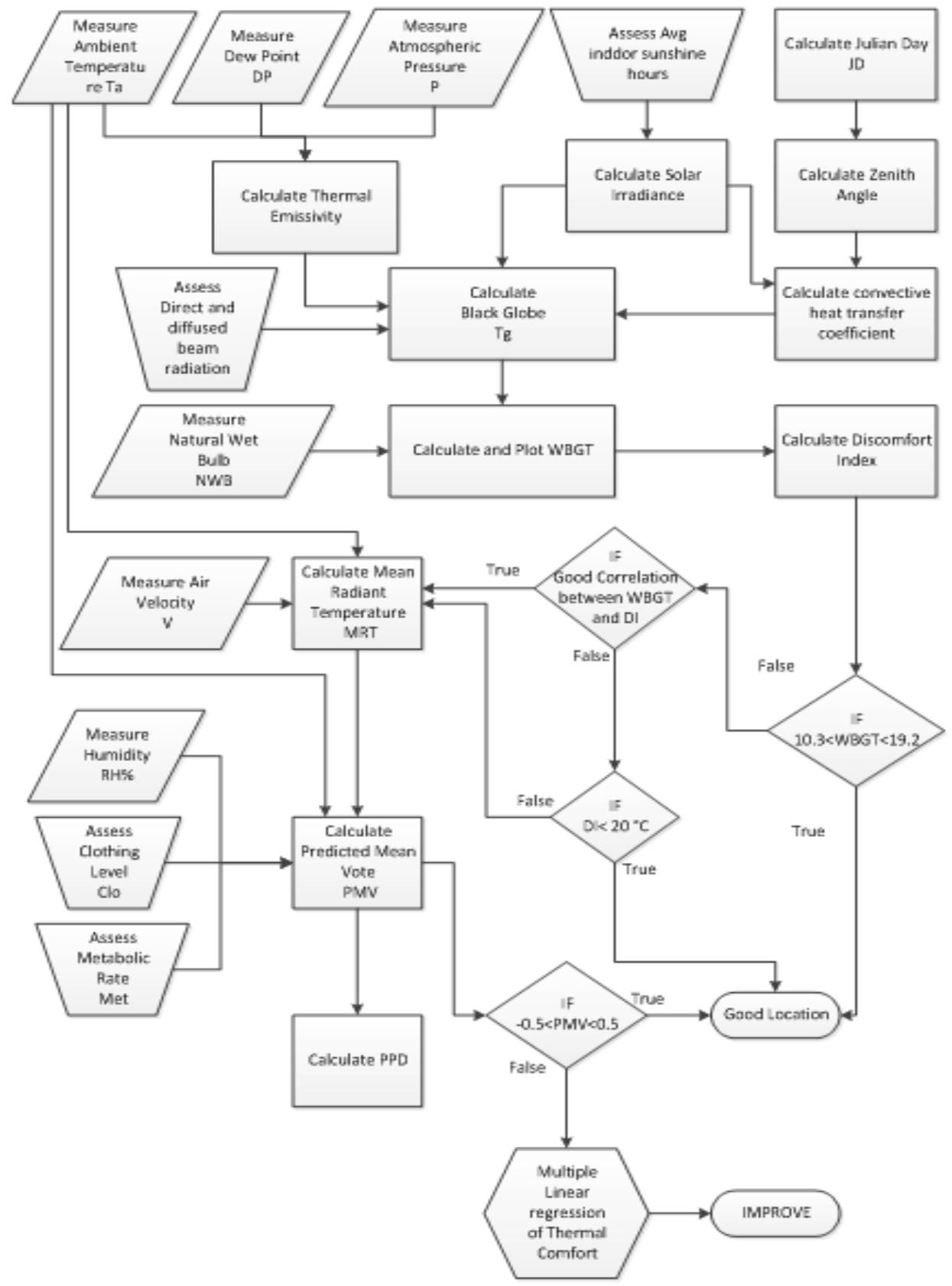

Figure 1. Heat Analysis Logic

As the chart indicates, the following steps were followed:

- Measure key heat variables such as $T_{a}, T_{w}, T_{d}, \mathrm{RH} \%$ and $\mathrm{V}$ using a Psychrometer and an anemometer

- Assess average indoor sunshine hours, $f_{d b}, f_{d i f}$ and calculate JD

- Calculate solar irradiation " $\mathrm{S}$ ", zenith angle " $\mathrm{Z}$ ", convective heat transfer coefficient " $\mathrm{h}$ " and thermal emissivity among others in order to calculate $T_{g}$ (see section 4.2) 
- After calculating $T_{g}$, move on to calculate WBGT (see section 4.2)

- If WBGT falls within limits and good correlation with DI (error proofing technique), then it is a thermally good location. If WBGT falls outside limits, depending on whether good correlation with DI, we move on (see section 4.2)

- If Good correlation between DI and WBGT, i.e. high correlation coefficient $R^{2}$, then accept WBGT and investigate further. If bad correlation, then if DI good conclude good location, otherwise investigate further

- Calculate MRT followed by an assessment of the Clothing level Clo and the Metabolic rate Met in order to calculate the Predicted Mean Vote PMV and Percentage of People Dissatisfied (see section 4.3)

If PMV falls within limits, then it is a good location. If PMV falls outside limits, then a multiple non-linear regression is performed to assess the impact of the different variables on the thermal condition and suggest improvements (see sections 5.2.2 and 5.3).

\subsection{WBGT}

\subsubsection{Algorithm of Estimation of the Globe Temperature}

As indicated in section 3.3, the WBGT is a primary index when investigating the thermal environment. However the globe temperature $T_{g}$ proves to be tiresome to measure and often inaccurate due to the inadequate conditions or use of the heat stress equipment. Also, the equipments have a high error rate of roughly $X^{+} 2_{-}{ }^{\circ}$ indoors and $X^{+} 3^{\circ}$ outdoors. So an excel file was prepared in which only key, easy to measure variables need to be indicated in order to estimate the globe temperature within $1 \%$ of actual reading with no need to purchase expensive equipment. Here are the steps:

\subsubsection{Measure and Enter Variables}

- Wind speed ( $U$ in meters/hour)

- Ambient Temperature ( $T_{a}$ in degrees Celsius)

- Dew point temperature ( $T_{d}$ in degrees Celsius)

- Direct beam radiation from the sun $\left(f_{d b}\right.$ in $\left.\%\right)$

- Diffuse radiation from the sun $\left(f_{\text {dif }}\right.$ in $\left.\%\right)$ 
N.B: The direct beam radiation and diffused beam radiation from the sun are fixed at 0.66 and 0.33 respectively during winter and during the summer at 0.75 and 0.25 respectively.

\subsubsection{Calculate Factors}

- Solar irradiance (S in Watts $/ \mathrm{m}^{2}$ )

The solar irradiance is calculated using an excel table similar to this one:

\begin{tabular}{|l|l|}
\hline $1-$ Avg indoor daily solar irradiance $\left(\mathrm{KWh} / \mathrm{m}^{2} /\right.$ day $)=$ & \\
\hline 2- \# of Indoor Sunshine Hours per day $=$ & \\
\hline $3-\mathrm{S}=($ Avg daily irradiance/\# of sunshine hours $) * 1000=$ \\
\hline
\end{tabular}

Table 6. Solar irradiance calculation

- The zenith angle

It is calculated using the following formula:

$$
Z=41+23.5 * \cos (J D)(e x: \text { November } 13=317 \mathrm{JD})
$$

N.B. the angle is converted to radians later on using the following conversion factor: 1 degree $=0.0174$ radians )

- The thermal emissivity

- Atmospheric vapor pressure:

$\mathrm{e}_{\mathrm{a}}=\exp \left(\frac{17.67\left(\mathrm{~T}_{d}-\mathrm{T}_{\mathrm{a}}\right)}{\mathrm{T}_{\mathrm{d}}+243.5}\right) *(1.007+0.00000246 \mathrm{P}) * 6.112 \exp \left(\frac{17.502 \mathrm{~T}_{\mathrm{a}}}{\left.240.97+\mathrm{T}_{\mathrm{a}}\right)}\right.$

- Thermal emissivity:

$$
\sum_{a}=0.575 e_{a}^{(1 / 7)}
$$

- Coefficients

$$
\begin{gathered}
\mathrm{B}=\mathrm{S}\left(\frac{\mathrm{f}_{\mathrm{db}}}{4 \sigma \cos (\mathrm{z})}+\frac{1.2}{\sigma} \mathrm{f}_{\mathrm{dif}}\right)+{ }_{\mathrm{a}} \mathrm{T}_{\mathrm{a}}^{(4)} \\
\mathrm{C}=\frac{h u^{(0.58)}}{5.3865 * 10^{-8}}
\end{gathered}
$$

Where convective heat transfer coefficient: 


$$
h=a\left(S^{b}\right)\left([\cos (Z)]^{b}\right)
$$

- Finally, calculate the globe temperature:

$$
\mathrm{T}_{\mathrm{g}}=\frac{\mathrm{B}+\mathrm{C} * \mathrm{~T}_{\mathrm{a}}+7680000}{\mathrm{C}+256000}
$$

\subsubsection{Discomfort Index DI and Error Proofing}

Also, an error proofing method was devised to make sure that the estimation technique of $T_{g}$ was successful, and it consists of calculating another heat stress index called Discomfort Index(DI) which is also widely used. The discomfort index was found to be highly correlated to the WBGT from empirical tests, and it will serve as a proof of the accurate estimation of the black globe $T_{g}$ in calculating WBGT. The equation of DI is as follows:

$$
\mathrm{DI}=0.5 * \mathrm{~T}_{\mathrm{w}}+0.5 * \mathrm{~T}_{\mathrm{a}}
$$

\subsection{PMV and PPD}

\subsubsection{MRT}

MRT is the next variable to be calculated using the following equation:

$$
M R T=(1+0.22 * \sqrt{ } v)\left(T_{g}-T_{a}\right)+T_{a}
$$

MRT is a particularly important variable because added to dry bulb $T_{a}$ we get the operative temperature, which what we actually feel:

$$
T_{\text {op }}=\frac{h_{r} * M R T+h_{c} * T_{a}}{h_{r}+h_{c}}
$$

or if the wind velocity does not exceed $0.2 \mathrm{~m} / \mathrm{s}$ on average,

$$
\mathrm{T}_{\mathrm{op}}=\frac{\mathrm{T}_{\mathrm{a}}+\mathrm{MRT}}{2}
$$

\subsubsection{PMV and PPD}

After calculating MRT, a holistic heat stress index is calculated, the PMV. Following the approach explained in section 3.2.2 earlier, the PMV was calculated using excel (N.B: Many online free 
PMV calculators exist, with the most easy one being CBE thermal comfort tool for ASHRAE 55 developed by Berkeley University, http://www.cbe.berkeley.edu/comforttool/)

First, enter the key variables listed below in Table 7 and The PMV, PPD and Operative temperature will be generated.

\begin{tabular}{|c|c|}
\hline Parameter & Input \\
\hline Clothing (clo $)$ & {$[0$ to $2 \mathrm{clo}]$} \\
\hline Air temp. $\left({ }^{\circ} \mathrm{C}\right)$ & {$\left[10\right.$ to $\left.30^{\circ} \mathrm{C}\right]$} \\
\hline Mean radianttemp. $\left({ }^{\circ} \mathrm{C}\right)$ & {$\left[10\right.$ to $\left.40^{\circ} \mathrm{C}\right]$} \\
\hline Activity $(\mathrm{met})$ & {$[0.8$ to $4 \mathrm{met}]$} \\
\hline Air speed $(\mathrm{m} / \mathrm{s})$ & {$[0$ to $1 \mathrm{~m} / \mathrm{s}]$} \\
\hline Relativehumidity $(\%)$ & {$[30$ to $70 \%]$}
\end{tabular}

Table 7. Sample PMV key variables

\section{Case Study}

The case study was conducted at one of the regional leading packaging company based on their request.

\subsection{WBGT Plot and Analysis}

Using the software DataFit available online, a polynomial non-linear regression was performed for the calculated WBGT and their corresponding coordinates in order to plot them and have a visual heat stress map. Here are the calculated WBGT and their corresponding coordinates:

\begin{tabular}{|r|r|r|c|c|}
\hline \multicolumn{1}{|l|}{$\mathbf{X}$} & \multicolumn{1}{|c|}{$\mathbf{Y}$} & \multicolumn{1}{|c|}{ WBGT } & Too Cold & Too Hot \\
\hline 68.6 & 27.8 & 26.77 & 0 & 1 \\
\hline 95.2 & 28.3 & 25.51 & 0 & 1 \\
\hline 34.3 & 25.8 & 26.54 & 0 & 1 \\
\hline 18.3 & 26.8 & 25.95 & 0 & 1 \\
\hline 49.2 & 9.2 & 25.14 & 0 & 1 \\
\hline 77.5 & 10.5 & 24.5 & 0 & 1 \\
\hline 29.6 & 66.9 & 24.47 & 0 & 1 \\
\hline 31.0 & 47.3 & 24.97 & 0 & 1 \\
\hline 30.8 & 80.1 & 23.38 & 0 & 1 \\
\hline 28.7 & 93.0 & 24.46 & 0 & 1 \\
\hline 43.9 & 61.3 & 24.68 & 0 & 1 \\
\hline 42.4 & 48.7 & 24.9 & 0 & 1 \\
\hline 21.8 & 91.8 & 23.23 & 0 & 1 \\
\hline 20.0 & 82.1 & 25.42 & 0 & 1 \\
\hline 14.8 & 122.2 & 23.28 & 0 & 1 \\
\hline 24.2 & 57.9 & 24.5 & 0 & 1 \\
\hline 23.5 & 46.4 & 24.7 & 0 & 1 \\
\hline 65.5 & 58.1 & 23.43 & 0 & 1 \\
\hline 84.7 & 56.9 & 23 & 0 & 1 \\
\hline
\end{tabular}

Table 8. WBGT and Coordinates 
N.B: A "0" means negative and a " 1 " means positive

Here is a plot of the WBGT:

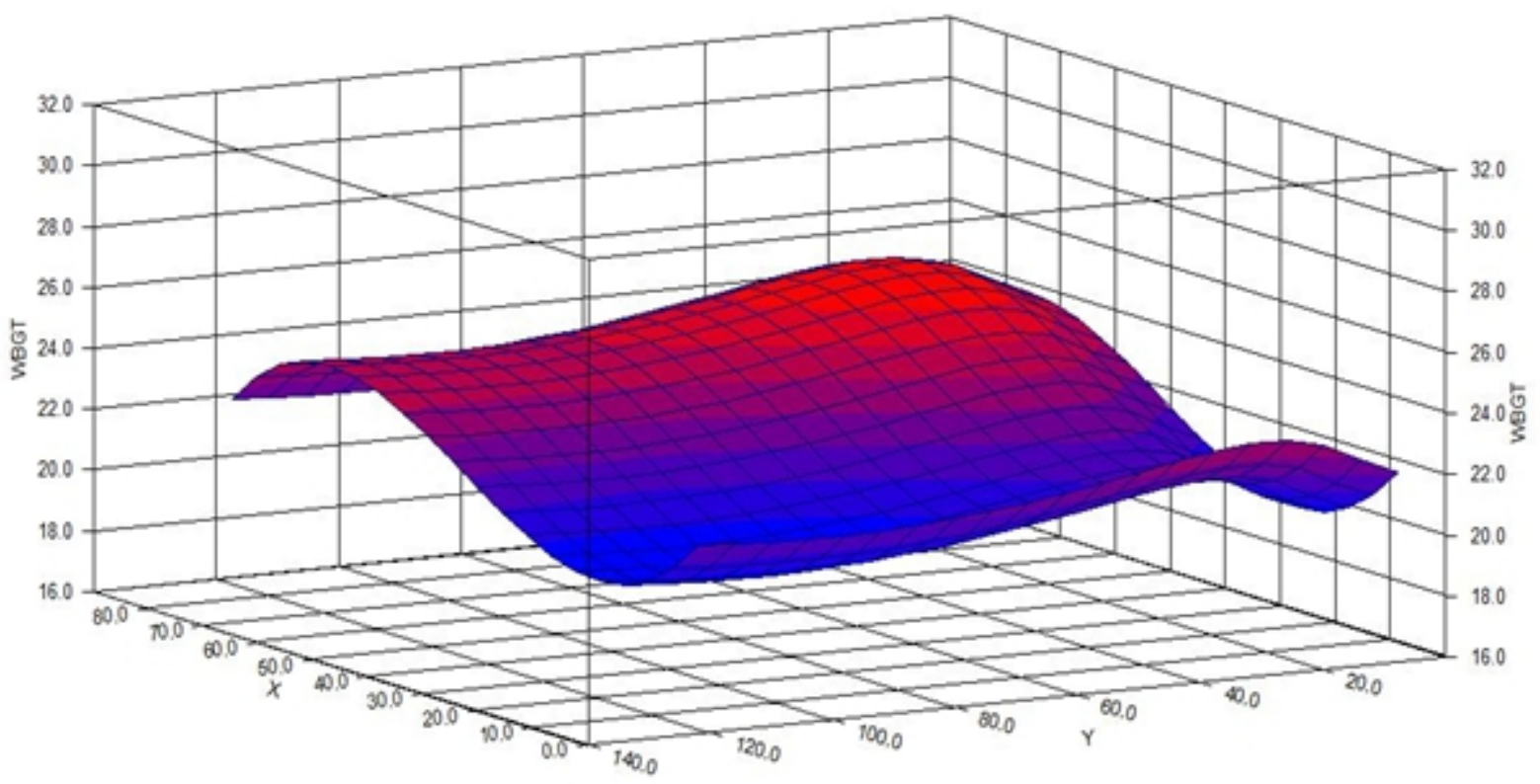

Figure 2. WBGT Plot

95.95\% of the WBGT falls outside the comfort range as indicated in the Plot above and more accurately in the calculated WBGT. So, an error proofing method is needed to validate the results. The discomfort index DI is calculated and a correlation test was made using excel between the calculated indexes, with a high correlation coefficient of 0.98 as indicated in the table below:

\begin{tabular}{|c|r|r|}
\cline { 2 - 3 } \multicolumn{1}{c|}{} & \multicolumn{1}{|c|}{ WBGT } & \multicolumn{1}{c|}{ DI } \\
\hline WBGT & 1 & \\
\hline DI & 0.987813 & 1 \\
\hline
\end{tabular}

Table 9. WBGT and DI correlation

So WBGT stands and one area calls for attention which is the mid section of the Combining 1 machine near the starch room where noticeable heat is emitted based on numerous personal visits. So, later on in the improvements, this area will be set as the main target for primary implementation. 


\subsection{PMV and PPD}

The following MRT's were calculated:

\begin{tabular}{|c|r|r|r|}
\cline { 2 - 4 } \multicolumn{1}{c|}{} & \multicolumn{3}{|c|}{ Mean RadiantTemperatureor MRT $\left({ }^{\circ} \mathbf{C}\right)$} \\
\hline Location & $\mathbf{1}$ & $\mathbf{2}$ & \multicolumn{1}{|c|}{$\mathbf{3}$} \\
\hline C2 & 41.13441054 & 30.27846952 & 30.41628891 \\
\hline C3 & 34.17867589 & 28.81659299 & 28.5508633 \\
\hline C4 & 37.33512652 & 25.57936584 & 25.31727179 \\
\hline A1 & 34.43567293 & 23.47976632 & 22.51781141 \\
\hline A2 & 32.47900009 & 29.01655445 & 28.35090221 \\
\hline I1 & 32.53636243 & 29.11653517 & 28.35090221 \\
\hline I2 & 33.03593671 & 27.77856487 & 29.3165009 \\
\hline B11 & 31.97909544 & 30.91618828 & 30.55047421 \\
\hline B12 & 32.77894288 & 31.61605337 & 31.15035749 \\
\hline B21 & 33.23589903 & 31.07831696 & 30.71623109 \\
\hline B22 & 33.03593671 & 26.87911792 & 26.51704052 \\
\hline BV1 & 30.07945778 & 25.6172097 & 25.35148584 \\
\hline BV2 & 33.8787331 & 27.91676644 & 27.25111621 \\
\hline P & 31.1362947 & 30.07850766 & 29.41648163 \\
\hline J1 & 32.67896195 & 26.41705552 & 25.45146639 \\
\hline J2 & 32.8359744 & 26.57917513 & 26.21709834 \\
\hline K1 & 31.67915265 & 28.31668935 & 28.15094112 \\
\hline K2 & 31.17924801 & 27.01693989 & 27.35109675 \\
\hline M1 & 33.33588019 & 29.27866023 & 28.31669362 \\
\hline M2 & 33.23589903 & 28.87873651 & 28.71661654 \\
\hline LMC1 & 33.43586135 & 28.17887 & 27.81678998 \\
\hline LMC2 & 33.23589903 & 29.8785458 & 29.41648163 \\
\hline It & 32.1790573 & 28.81659299 & 27.75101894 \\
\hline AS & 31.6362005 & 30.27846952 & 29.21652018 \\
\hline L1 & 33.5358425 & 27.17906071 & 26.21709834 \\
\hline L2 & 33.33588019 & 27.37902257 & 27.01694416 \\
\hline St & 32.1790573 & 28.81659299 & 28.75082439 \\
\hline Sh & 32.93595555 & 26.67915606 & 26.31707907 \\
\hline SR & 31.1362947 & 28.77875558 & 28.31669362 \\
\hline O1 & 28.53678459 & 28.57879372 & 28.41667435 \\
\hline O2 & 29.03669038 & 28.57879372 & 28.41667435 \\
\hline D & 36.23533378 & 34.87759228 & 34.81544094 \\
\hline & & & \\
\hline
\end{tabular}

Table 10. MRT

Following the approach explained in section 2.1 earlier, the PMV was calculated using Excel. The PMV for each measurement point and then the average PMV, PPD and Top were calculated.

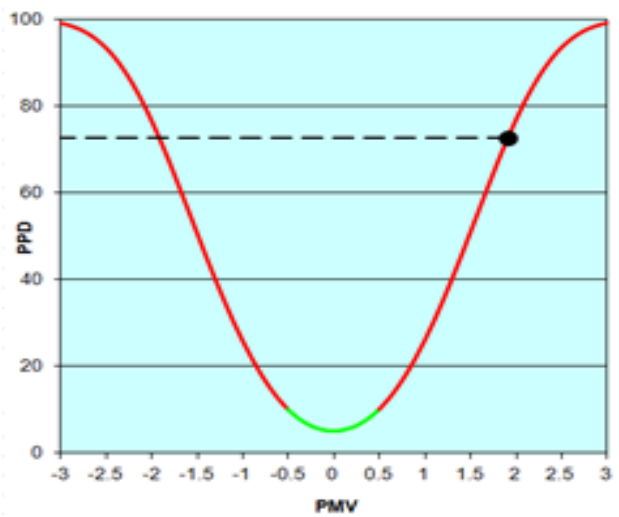

Figure 3. Average PPD Graph 
On average, $\mathrm{PMV}=1.91, \mathrm{PPD}=72.8 \%$ and $\mathrm{T}_{\mathrm{op}}=27.76^{\circ} \mathrm{C}$. All of the PMV's fell outside the comfort range, so an in-depth look at the impact of the different variables is in order.

\subsubsection{PMV Linear Regression}

A regression was performed using the calculated PMV's and the 6 relevant parameters to have an idea about the impact of each of these parameters on the Predicted Mean Vote. The coefficients in the equation gave no clear importance to specific variables. One probable reason is because the clothing level Clo variable and the metabolic rate met are constant or near constant throughout the sample points, which is an inherent uncertainty in the PMV calculation. So a second regression using the software DataFit was performed using only the 4 varying variables, MRT, $T_{a}, R H \%$ and $V$, in order to catch their contribution to the high PMV's. The following equation was derived $(R \wedge 2=0.992)$ :

$$
\begin{gathered}
\mathrm{PMV}=-3098.53237148735 * \mathrm{Ta}+3099.28214128384 * \mathrm{MRT}+- \\
2662.09303769639 * \mathrm{~V}+6.7916998578212 \mathrm{E}-03 * \mathrm{RH} \%+-10579.811499243
\end{gathered}
$$

As expected the two highest influencers of the PMV are the MRT and T_a with equal yet opposite signs coefficients, as well a considerable contribution by the wind velocity. Since the Wind velocity is a key input when calculating MRT and $\mathrm{RH} \%$ is an independent factor when calculating PMV, Dry-Bulb, $\mathrm{RH} \%$ with the collateral factor of Wind velocity are the key parameters to focus on to relax the comfort zone.

\subsection{Improvements}

When suggesting possible improvements, one has to be able to assess their importance in terms of how much they relax the comfort zone, and by consequence help to bring the thermal environment to conform to the international standards, most importantly ASHRAE 55 which is used in this analysis as a reference (Note that the software Climate Consultant 5.4 can be used to draw the psychrometric charts and assess the improvements based on ASHRAE 55).

Here is the comfort zone in this case with sample points drawn on the psychrometric chart: 


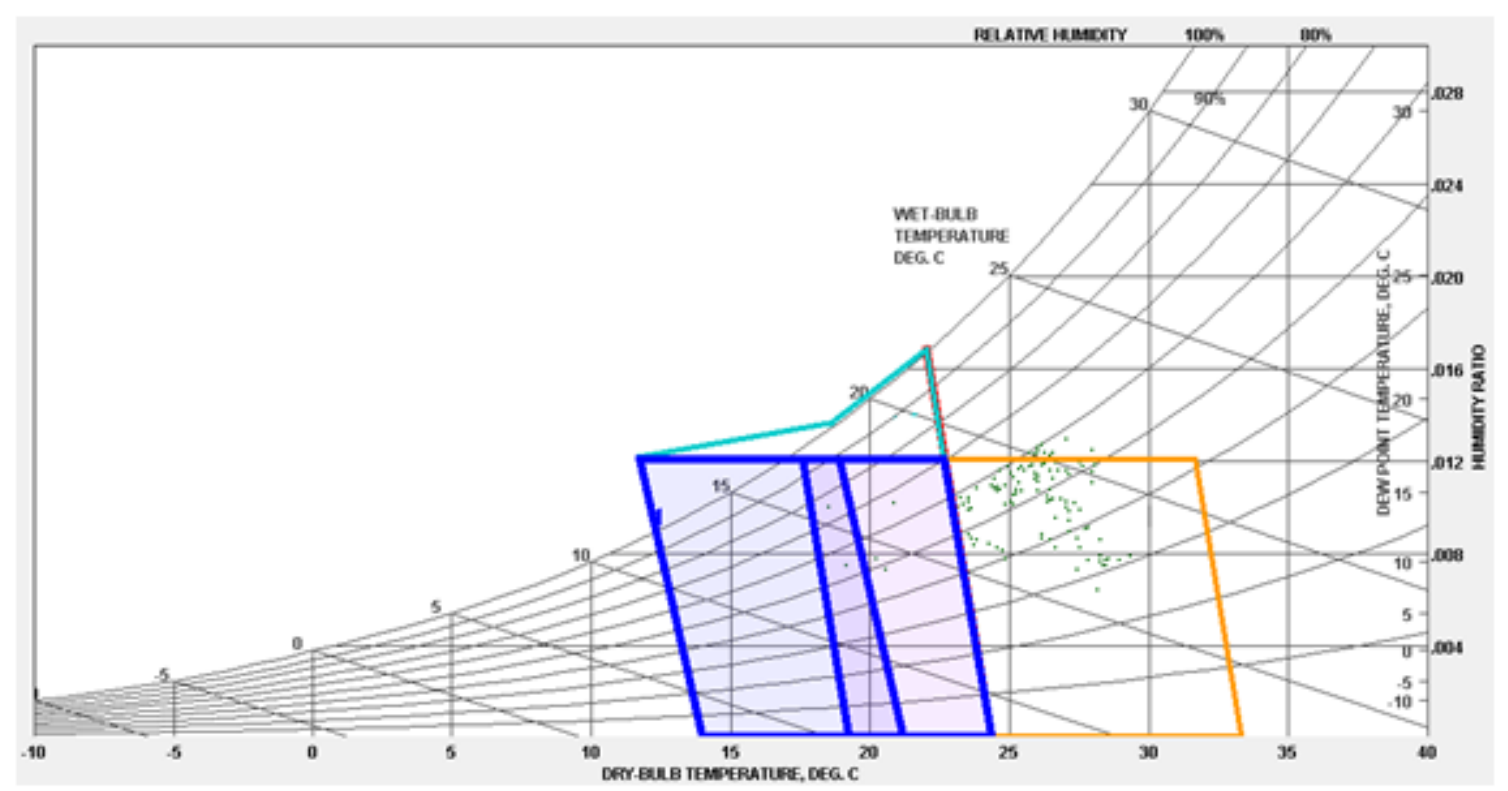

Figure 4. Psychrometric chart (generated in software Climate Consultant 5.4)

Based on the ASHRAE 55 standards, the improvements are:

- First, need to raise the tolerance of dry bulb temperature $T_{a}$

- Second, raise the tolerance of relative humidity $\mathrm{RH} \%$ by just a little

This conforms to the findings from the PMV regression, i.e. high coefficient for $\mathrm{T}_{\mathrm{a}}$ and $\mathrm{RH} \%$. So, when investigating what would bring the majority of the out-of-comfort points, the following three are primal:

- Cooling and dehumidification

- High thermal mass

- Direct evaporative cooling

The cooling, dehumidification and simple building techniques such as high thermal mass increase the tolerance of $\mathrm{RH} \%$ as well as wet bulb and dry bulb and would bring the majority of the points inside the comfort range.

In order to have a high thermal mass building that provides "inertia against temperature fluctuations", a couple of building techniques could be utilized such as High mass walls, ceiling insulation and high solar reflectance index (SRI) materials.

Also, there exist natural ventilation systems which are optimal for the following reasons: 
- Energy efficiency (savings between 10 and 30\% from typical HVAC systems): Occupants of naturally ventilated buildings are often more tolerant of fluctuations in the indoor climate. They tend to accept a wider range of temperature and humidity levels, allowing for the thermostatic set-point to be raised slightly in the summer and lowered slightly in the winter. This leads to reduced energy consumption by mechanical equipment.

- Improve indoor environmental quality: Controlling the MRT and not the $T_{a}$, because it is what occupants actually feel

- Minimal maintenance: Simply because there are less mechanical parts

N.B: In order to be able to rely on such systems, they should be installed in buildings that apply high thermal mass and evaporative cooling as well. This way, the needs for mechanical (air chillers or chilled water) systems are minimized if not eliminate.

\section{Conclusions}

Most companies are oblivious to the benefits of conducting regular indoor environmental assessment tests, especially for the thermal environment. With a comfortable thermal environment comes a productive worker. The proposed methodology hopes to provide a systematic multi-disciplinary approach to assessing the thermal environment. A company or the concerned individual will be able to follow this new methodology with minimal wasted resources and time in unnecessary steps whilst providing a guideline for a detailed study with minimal error rates if needed.

\section{References}

Ai, Z., Mak, C., Niu, J., \& Li, Z. (2011). Effect of balconies on thermal comfort in wind-induced, naturally ventilated low-rise buildings. Building Services Engineering Research \& Technology, 32(3), 277-292. http://dx.doi.org/10.1177/0143624410396431

Alahmer, A.I. (2009). Effect of relative humidity and temperature control on in-cabin thermal comfort state. Applied Thermal Engineering, 31(14-15), 2636-2644. http://dx.doi.org/10.1016/j.applthermaleng.2011.04.033

Budd, G.M. (2008). Wet-bulb globe temperature (WBGT) - its history and its limitations. Journal of Science and Medicine in Sport, 11(1), 20-32. http://dx.doi.org/10.1016/j.jsams.2007.07.003 
Chamra, L.M., Steele, W.G., \& Huynh, K. (2003). The uncertainty associated with thermal comfort. ASHRAE Transactions, 109, 356-365.

Chan, P.C., Michael Yam, C.H., Joanne Chung, W.Y., \& Wen, Y. (2012). Developing a heat stress model for construction workers. Journal of Facilities Management, 10(1), 59-74. http://dx.doi.org/10.1108/14725961211200405

Chandra, A., Ghosh, S., \& Barman, S. (2010). Effect of Exercise and Heat-Load on Simple Reaction Time of University Students. International Journal of Occupational Safety and Ergonomics, 16(4), 497-505. http://dx.doi.org/10.1080/10803548.2010.11076862

Chen, T.H., Lin, C.L., \& Wang, M.J. (2012). The evaluation of double-layer clothing in a semiconductor manufacturing environment. Human Factors and Ergonomics in Manufacturing and Service Industries, 24(2), 207-215. http://dx.doi.org/10.1002/hfm.20369

Dimiceli, V., Piltz, S., \& Amber, S. (2011). Estimation of Black Globe Temperature to Estimate the Wet Bulb Globe Temperature Index. Proceedings of the World Congress on Engineering and Computer Science, Vol. 2.

Epstein, Y., \& Moran, D. (2006). Thermal Comfort and the heat stress indices. Industrial Health, 44, 388-398. http://dx.doi.org/10.2486/indhealth.44.388

Hancock, P.A., \& Vasmatzidis, I. (2003). Effects of Heat Stress on Cognitive Performance: The Current State of Knowledge. International Journal of Hyperthermia, 19(3), 355-372. http://dx.doi.org/10.1080/0265673021000054630

Ismail, A.R., Rani, M., Makhbul, Z., \& Deros, B.M. (2009). Assessment of Thermal Comfort and Optimization of Environmental Factors at Automotive Industry. European Journal of Scientific Research, 31(3), 409-423.

Kumar, N., Kumar, S., Haleem, A., \& Gahlot, P. (2013). Implementing Lean Manufacturing Systems: ISM Approach. Journal of Industrial Engineering and Management, 6(4), 996-1012. http://dx.doi.org/10.3926/jiem.508

Lu, J. (2008). Occupational Hazards and Illness of Filipino Women Workers in Export Processing Zones. International Journal of Occupational Safety and Ergonomics, 14(3), 333-342. http://dx.doi.org/10.1080/10803548.2008.11076771

Marksberry, P., \& Parsley, D. (2011). Managing the IE (Industrial Engineering) Mindset: A quantitative investigation of Toyota's practical thinking shared among employees. Journal of Industrial Engineering and Management, 4(4), 771-799. http://dx.doi.org/10.3926/jiem.293 
Othman, M., Gouw, G., \& Bhuiyan, N. (2012). Work force scheduling: A new model in corporating human factors. Journal of Industrial Engineering and Management, 5(2), 259-284. http://dx.doi.org/10.3926/jiem.451

Richards, M., Rossi, R., Meinander, H., Broede, P., Candas, V., Den Hartog, E., et al. (2008). Dry and Wet Heat Transfer Through Clothing Dependent on the Clothing Properties Under Cold Conditions. International Journal of Occupational Safety and Ergonomics, 14(14), 69-76. http://dx.doi.org/10.1080/10803548.2008.11076750

Wang, F., Gao, C., Kuklane, K., \& Holmer, I. (2010). A review of Technology of Personal Heating Garments. International Journal of Occupational Safety and Ergonomics, 16(3), 387-404. http://dx.doi.org/10.1080/10803548.2010.11076854

Wildeboor, J., \& Camp, J. (1993). Heat stress: Its Effect and Control. AAOHN Journal, 41(6), 268-274.

Article's contents are provided on an Attribution-Non Commercial 3.0 Creative commons license. Readers are allowed to copy, distribute and communicate article's contents, provided the author's and Journal of Industrial Engineering and Management's names are included. It must not be used for commercial purposes. To see the complete license contents, please visit http://creativecommons.org/licenses/by-nc/3.0/. 